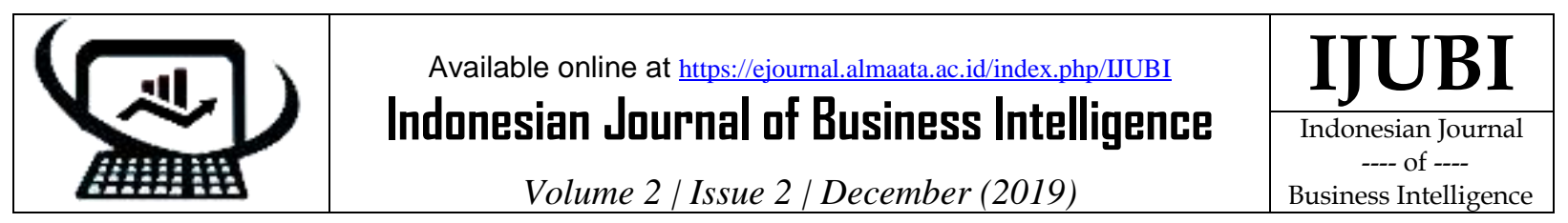

\title{
IMPLEMENTASI METODE WATERFALL PADA PERANCANGAN SISTEM INFORMASI PELAYANAN RAWAT JALAN PUSKESMAS TELAGASARI KARAWANG
}

Muhamad Tabrani ${ }^{1}$, Zaenal Mutaqin ${ }^{2}$

1Teknik Informatika, STMIK Nusa Mandiri

2Sistem Informasi, Fakultas Teknologi Informasi, Universitas Bina Sarana Informatika

${ }^{1}$ muhamad.mtb@nusamandiri.ac.id, ${ }^{2}$ zaenal13180839@bsi.ac.id

${ }^{1}$ Jl. Damai No.8 Warung Jati Barat (Margasatwa) Jakarta Selatan

${ }^{2}$ Jl. Kamal Raya No. 18 Ringroad Barat, Cengkareng, Jakarta Barat

\section{Keywords:}

Website

puskesmas

Services. design, In the current era of globalization, information technology is advancing health rapidly. Every government and self-government institution is even required to be able to present information quickly and accurately in the world of work. In this case the computer has an important role for everyone, because computers are one of the fastest media to facilitate the presentation of information quickly and accurately. In the world of work such as health services in health centers whose activities are still carried out manually and have not been maximally computerized, so that it will cause several problems that can reduce the performance of services to the community, such as a long service time. For this reason the author makes a website Designing a Web-Based Outpatient Information System at the Telagasari Health Center in Karawang to support services and provide better services in the future. The method used in developing this software uses the Waterfall method, starting with 1) software requirements analysis 2) Design 3) making program code 4) testing 5) Maintenance. With the help of website design that has a data storage system that is supported by its security, it is expected that service and reporting activities can run effectively and also to minimize the error or data loss that is carried out by service personnel at the puskesmas so as to produce a fairly good program. Website design at this puskesmas has also been carried out by functional testing using the black-box method.

\section{Kata Kunci}

Perancangan web,

Pelayanan kesehatan puskesmas.

\section{Abstrak}

Dalam era globalisasi sekarang ini, teknologi informasi melaju dengan cepatnya. Setiap lembaga pemerintahan maupun swasata bahkan setiap orang dituntut untuk dapat menyajikan informasi dengan cepat dan akurat dalam dunia kerja. Dalam hal ini komputer mempunyai peranan penting bagi setiap orang, karena komputer merupakan salah satu media yang paling cepat untuk memfasilitasi sajian informasi dengan cepat dan akurat. Dalam dunia kerja seperti pelayanan kesehatan di puskesmas yang kegiatannya masih dilakukan secara manual dan belum terkomputerisasi secara maksimal, sehingga akan menimbulkan beberapa permasalahan yang dapat mengurangi kinerja pelayanan kepada masyarakat, seperti waktu pelayanan yang cukup lama. Untuk itulah penulis membuat website Perancangan Sistem Informasi Pelayanan Rawat Jalan Berbasis Web Pada Puskesmas Telagasari Karawang untuk menunjang pelayanan dan memberikan pelayanan yang lebih baik lagi kedepannya. Metode yang digunakan dalam pengembangan perangkat lunak ini menggunakan metode Waterfall, dimulai dari 1)analisa kebutuhan perangkat lunak 2) Desain 3) pembuatan kode program 4) pengujian 5) Pemeliharaan. Dengan bantuan perancangan website yang mempunyai sistem 
penyimpanan data yang didukung keamanannya, diharapakan kegiatan pelayanan dan pelaporan dapat berjalan efektif dan juga untuk meminimalisir kesahalan atau kehilangan data yang dilakukan oleh petugas pelayanan di puskesmas sehingga menghasilkan suatu program yang cukup baik. Perancangan website pada puskesmas ini juga telah dilakukan pengujian secara fungsional dengan metode black-box.

\section{Pendahuluan}

Perkembangan teknologi mengalami kemajuan yang sangat pesat, semakin hari teknologi semakin canggih, kenyataan ini menuntut keterlibatan sumber daya manusia agar mampu menangani dan memanfaatkan teknologi yang ada semaksimal mungkin. Laju perkembangan teknologi memiliki pengaruh yang cukup besar dalam segala bidang kehidupan, salah satunya pada bidang kesehatan yaitu pada pelayanan kesehatan di puskesmas menjadikan komputer sebagai salah satu alat penunjang yang dibutuhkan dalam pelayanan di puskesmas yaitu dalam pengolahan data dan penyajian data informasi yang berkaitan dengan data kunjungan pasien karena teknologi komputerisasi ini memiliki loyalitas penyimpanan data yang cukup besar serta dukungan keamanan data yang terjamin dengan sistem komputerisasi yang efisien sehingga menghasilkan informasi yang akurat, tepat waktu dan tepat guna.

Namun banyak puskesmas yang masih belum menerapkan penuh sistem informasi untuk menunjang kegiatan mereka. Salah satunya ialah Puskesmas Telagasari. Dengan sistem yang masih tergolong manual, terutama dibagian pendaftaran dan pelayanan rawat jalan pasien di puskesmas karena masih menggunaan buku register manual untuk pencatatan data pendaftaran dan pelayanan pasien sehingga dengan begitu banyaknya data pasien (Rekam Medis) yang ada yang berbentuk buku dan tersimpan dalam lemari. Apabila ada pasien yang tidak membawa kartu pasien pada saat berkunujung atau berobat ke puskesmas akan menyulitkan petugas dalam mencari data atau rekam medis pasien tersebut, sehingga menjadi tidak efektif dan efisien dalam hal waktu pelayanan pasien karena akan memakan waktu yang lama hanya mencari satu data pasien teebut saja, Oleh karena itu untuk memecahkan permasalahan yang terjadi pada pelayanan rawat jalan di Puskesmas tersebut maka di perlukan sistem aplikasi untuk mempermudah petugas dalam hal proses Pelayanan kepada pasien yang lebih cepat, tepat, dan akurat dengan adanya sistem program aplikasi tersebut diharapkan dapat membantu puskesmas dalam pelayanan di puskesmas menjadi lebih baik lagi dan dapat mempercepat atau mempersingkat waktu pelayanan rawat jalan terhadap pasien yang datang berobat.

Menurut Wibisono \& Munawaroh dalam (Syahriani, 2018) mengemukakan bahwa "Supaya data yang telah diarsipakan dapat mudah dicari dan dapat tersusun rapi, maka penggunaan komputer untuk pengolahan data pasien sangat diperlukan, guna memberikan beberapa keuntungan dan kemudahan dalam pelayanan pasien, antara lain: mempercepat pelayanan, informasi yang lebih akurat dan pencarian data yang lebih cepat".

Apalagi dengan kedepannya puskesmas akan menggunakan aturan baru yaitu BLUD (Badan Layanan Umum Daerah) yang artinya puskesmas dapat mengelola manajemen dan keuangannya secara mandiri, sehingga dengan begitu agar puskesmas segera berbenah dalam pelayanan rawat jalan ke masyarakat pasien dengan menggunakan program aplikasi dapat membantu proses pelayanan rawat jalan yang berlangsung di puskesmas sehingga nantinya pelayanan rawat jalan di puskesmas dapat lebih efektif dan efisien sehingga puskesmas juga tidak kalah bersaing dengan fasilatas fasilitas kesehatan lainnya seperti klinik - klinik swasta yang sudah menggunakan program aplikasi terlebih dahulu dibanding puskesmas. 


\section{Metode Penelitian}

Adapun metode dan teknik pengumpulan data yang digunakan oleh penulis adalah :

\section{Metode Pengembangan Perangkat Lunak}

Metode yang digunakan dalam pengembangan perangkat lunak ini menggunakan metode waterfall Menurut Sukamto dan Shalahuddin dalam (Sagita \& Sugiarto, 2016) mengungkapkan bahwa "Dalam hal pengembangan serta perencanaan sistem perangkat lunak penulis menggunakan metode pengembangan perangkat lunak model air terjun (waterfall)". Berikut adalah penjelasan metode penelitian model waterfall :

\section{a. Analisis Kebutuhan Perangkat Lunak}

Menganalisa kebutuhan sistem perangkat lunak yang yang dibutuhkan dalam program sistem rawat jalan di puskesmas sehingga akan tercipta sebuah apliikasi rawat jalan puskesmas yang dapat melakukan tugas-tugas yang diinginkan oleh petugas di puskesmas seperti melakukan pendaftaran pasien, pemeriksaan pasien, penanganan pasien, pengobatan pasien, pemabaaran penangana pasien, laporan kunjungan dan laporan pendapatan puskesmas.

\section{b. Desain}

Pada tahapan desain ini penulis akan merancang desain dan pada tahapan desain ini yang dilakukan adalah membuat rancangan antarmuka program, rancangan basis data dan rancangan struktur navigasi pada program tersebut sesuai dengan kebutuhan yang dibutuhkan.

\section{c. Pembuatan Kode Program}

Dalam tahap pembuatan aplikasi pemrograman, hasil analisis dan desain sistem pada proses sebelumnya diimplementasikan ke dalam bentuk program aplikasi menggunakan bahasa pemograman Codeigneter, Jquery, PHP, HTML.

\section{d. Pengujian}

Tahap pengujian ini dilakukan setelah kode program selesai dibuat dan program dapat berjalan untuk menguji apakah kode program sudah berjalan sesuai dengan yang diharapkan penulis dalam pembuatan program tersebut.

e. Pendukung (support) atau Pemeliharaan (maintenance)

Dan tahap pemeliharaan sistem ini adalah pemeliharaan secara rutin meliputi melakukan backup database untuk menjaga data - data yang terdapat dalam program aplikasi tersebut.

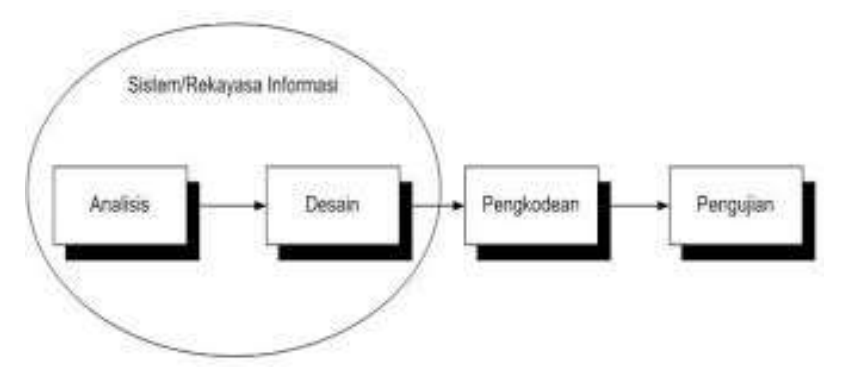

Gambar 1. Metode Penelitian

Sumber: (Sukamto dan Shalahuddin, 2016)

\section{Teknik Pengumpulan Data}

a. Observasi

Penulis melakukan pengamatan langsung ke UPTD Puskesmas Telagasari untuk mengetahui bagaimana sistem pelayanan kesehatan yang berjalan di UPTD Puskesmas Telagasari.

\section{b. Wawancara}

Selain melakukan observasi penulis juga melakukan wawancara kepada Bapak Arif Rusman petugas loket pendaftaran di UPTD Puskesmas Telagasari untuk mengetahui permasalahan apa saja yang dihadapi dalam melakukan pelayanan kesehatan.

\section{c. Studi Pustaka}

Untuk melengkapi informasi yang berhubungan dengan judul tugas akhir ini, penulis mengumpulkan referensi yang diperlukan dengan mencarinya di buku-buku, jurnal dan artikel di perpustakaan atau toko buku maupun yang ada di intenet. 


\section{Landasan Teori}

\section{Website}

Menurut (Hendriansyah, 2014) menyimpulkan bahwa "Website atau situs adalah kumpulan halaman yang menampilkan informasi data teks, data gambar diam atau gerak, data animasi, suara, video dan atau gabungan dari semuanya, baik yang bersifat statis maupun dinamis yang membentuk satu rangkaian bangunan yang saling terkait dimana masingmasing dihubungkan dengan jaringan-jaringan halaman (Hyperlink)".

\section{Internet}

Menurut Irawan dalam (Sagita \& Sugiarto, 2016) bahwa "internet merupakan kependekan dari kata internet network, yang berarti rangkaian komputer yang terhubung menjadi beberapa rangkaian, dimana sistem komputer terhubung secara global dan menggunakan TCP/IP sebagai protocol "

\section{Web Server}

Menurut Kurniawan dalam (Sagita \& Sugiarto, 2016) mengemukakan bahwa "Server Web adalah sebuah perangkat lunak yang berfungsi menerima permintaan http atau https dari klien yang dikenal dengan web browser dan mengirimkan kembali hasilnya dalam bentuk halaman-halaman web yang umumnya berbentuk dokumen html".

\section{Web Browser}

Menurut Sibero (Sagita \& Sugiarto, 2016) mengemukakan bahwa "Web Browser adalah aplikasi perangkat lunak yang digunakan untuk mengambil dan menyajikan sumber informasi web".

\section{Sistem}

Menurut (Lukman Ahmad, 2018) "Sistem adalah suatu susunan yang teratur dari kegiatan-kegiatan yang saling berkaitan dan susunan prosedur-prosedur yang saling berhubungan, sinergi dari semua unsurunsur dan elemen-elemen yang ada didalamnya, yang menunjang pelaksanaan dan mempermudah kegiatan-kegiatan utama tercapai dari suatu organisasi ataupun kesatuan kerja."

\section{Informasi}

Menurut Budi Sutejo dalam (Lukman Ahmad, 2018) Informasi merupakan hasil pemprosesan data yang diperoleh dari setiap elemen sistem tersebut menjadi bentuk yang mudah dipahami dan merupa pengetahuan yang relevan dan dibutuhkan dalam pemahaman fakta-fakta yang ada.

\section{Sistem Informasi}

Menurut (Kadir, 2014) menyimpulkan "bahwa sistem informasi mencakup sejumlah komponen (manusia, komputer, teknologi informasi, dan prosedur kerja), ada sesuatu yang di proses (data menjadiinformasi), dan dimaksudkan untuk mencapai suatu sasaran atau tujuan."

\section{Pelayanan Kesehatan}

Pelayanan Kesehatan dalam Perturan Menteri Kesehatan Republik Indonesia Nomor 75 tahun 2014 adalah "upaya yang diberikan oleh Puskesmas kepada masyarakat, mencakup perencanaan, pelaksanaan, evaluasi, pencatatan, pelaporan, dan dituangkan dalam suatu sistem".

\section{Puskesmas}

Dalam Perturan Menteri Kesehatan Republik Indonesia Nomor 75 tahun 2014 "Pusat Kesehatan Masyarakat adalah fasilitas pelayanan kesehatan yang menyelenggarakan upaya kesehatan masyarakat dan upaya kesehatan perseorangan tingkat pertama, dengan lebih mengutamakan upaya promotif dan preventif, untuk mencapai derajat kesehatan masyarakat yang setinggi-tingginya di wilayah kerjanya".

\section{Bahasa Pemograman}

\section{HTML (Hyper Text Markup Language)}

Menurut Hidayatullah dan Kawistara dalam (E. Fridayanthie, 2016) "Hyper Text Markup Language atau HTML adalah bahasa standar yang digunakan untuk menampilkan halaman web". Yang bisa dilakukan dengan HTML yaitu:

a. Mengatur tampilan dari halaman web dan isinya,

b. Membuat tabel dalam halaman web 
c. Mempublikasikan halaman web secara online.

d. Membuat form yang bisa digunakan untuk menangani registrasi dan transaksi via web.

e. Menambahkan objek-objek seperti citra, audio, video, animasi, java aplet dalam halaman web, serta menampilkan area gambar (canvas) di browser.

\section{PHP (Perl Hypertext Preprocessor)}

Menurut Kristanto dalam (E. Fridayanthie, 2016), "PHP adalah bahasa pemrograman yang digunakan secara luas untuk penanganan pembuatan dan pengembangan sebuah web dan bisa digunakan pada HTML". Adapun kelebihan-kelebihan dari PHP yaitu:

a. PHP merupakan sebuah bahasa script yang tidak melakukan sebuah kompilasi dalam penggunaannya. Tidak seperti halnya bahasa pemrograman aplikasi yang lainnya.

b. PHP dapat berjalan pada web server yang dirilis oleh Microsoft, seperti IIS atau PWS juga pada apache yang bersifat open source.

c. Karena sifatnya yang open source, maka perubahan dan perkembangan interpreter pada PHP lebih cepat dan mudah, karena banyak milis-milis dan developer yang siap membantu pengembanganya.

d. Jika dilihat dari segi pemahaman, PHP memiliki referensi yang begitu banyak sehingga sangat mudah untuk dipahami.

e. PHP dapat berjalan pada 3 (tiga) operating system, yaitu: Linux, unux, dan windows, dan juga dapat dijalankan secara runtime pada suatu console.

f. PHP bersifat bebas dipakai (free).

\section{JQuery}

Menurut Saputra dan Agustin dalam (Kadek Wibowo, 2015) mengemukakan bahwa "Jquery merupakan salah satu teknik atau kumpulan library javascript yang sangat terkenal dengan animasinya. Dengan sedikit sentuhan, animasi dalam website mudah kita ciptakan. Jquery dapat dianggap sebagai frameworknya javascipt".

\section{Codeigneter}

Menurut Lukmanul Hakim dalam (Prabowo, 2015) mengemukakan : "Codeigneter adalah sebuah framework untuk web yang dibuat dalam format PHP." Sejarah codeigneter awalnya dilahirkan Oleh ElisLab dirilis pertama kali pada tanggal 28 Februari 2006 pada sekitar bulan Oktober 2014, Kampus BCIT (British Columbia Institute of Technology) mengambil alih framework ini dan terus berkembang dari versi 2.2.6 ke versi yang terbaru 3.x. Codeigneter ini dapat memudahkan pengembang (developer) damalm membuat sebuah aplikasi web dengan cepat dan mudah dibanding dengan membuatnya dari awal.

\section{Sejarah Institusi/Perusahaan}

UPTD Puskesmas Tela-gasari berdiri pada tahun 1935 di atas tanah milik desa Tela-gasari seluas $1350 \mathrm{~m} 2$ yang ber-lokasi di dusun krajan I rt 08 rw 03 desa Telagasari Kabupaten Karawang. Sebelum Puskesmas Telagasari berdiri telah dibangun:

1. Balai Pengobatan pada tahun 1940 yang dikepalai oleh Bp. Asmawi.

2. Pada tahun 1945 diganti menjadi Klinik yang dikepalai oleh Bp. Slamet Purnomo.

3. Pada tahun 1969 menjadi Pusk-esmas yang dikepalai oleh Bp. Slamet.

4. Dan sekarang tetap menjadi UPTD Puskesmas Telagasari.

Adapun Visi dan Misi UPTD Pusk-esmas Telagasari:

Visi : “Terwujudnya kemandirian masyarakat kecamatan Telagasari untuk hidup sehat, dilandasi iman dan takwa."

Misi :

1. Meningkatkan perilaku hidup bersih dan sehat (PHBS) di wilayah kerja Puskemas.

2. Meningkatkan kualitas pelayanan di Puskesmas.

3. Meningkatkan profesionalisme petugas Puskesmas.

4. Meningkatkan disiplin kerja karya-wan.

5. Meningkatkan hubungan lintas pro-gram dan lintas sektoral. 


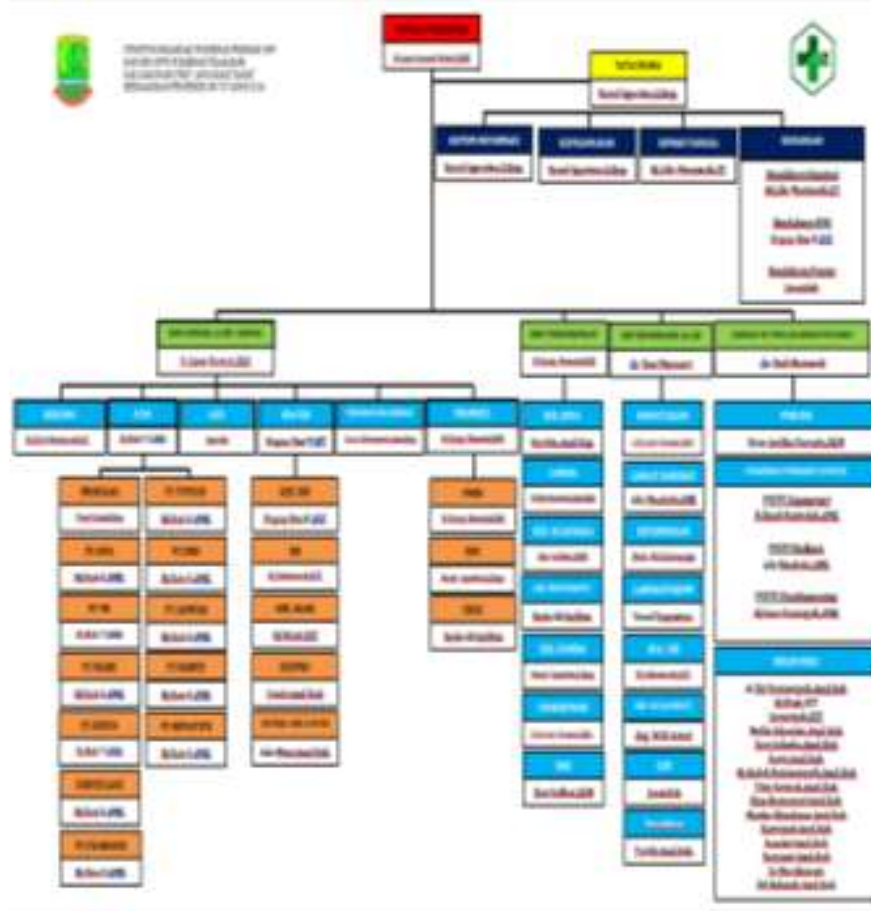

Gambar 2. Struktur Organisasi UPTD

Puskesmas Telagasari

Sumber: Data Puskemas Telagasari

\section{Analisa Kebutuhan}

\section{Analisis Kebutuhan Sistem}

Pelayanan pada puskesmas saat ini masih dilakukan secara manual pelayanan secara manual ini membutuhkan waktu lama dalam pelayanan sehingga tidak efektif dalam hal segi waktu.

Berdasarkan permasalahan diatas maka dibutuhkan sebuah sistem pelayanan di puskesmas yang diharapakan dapat memberi solusi dalam menghemat waktu pelayanan yang sebelumnya banyak memakan waktu yang cukup lama menjadi lebih efisien.

Tahapan selanjutnya adalah mengidentifikasi kebutuhan sistem yang akan dibuat. Perancangan sistem yang akan dibuat harus mendukung efektifitas sistem. Adapun sistem informasi yang akan dibuat diantaranya :

1. Sistem informasi ini dilengkapi dengan form login untuk membatasi atau memberikasn hak akses untuk beberapa karyawan saja.

2. Sistem dapat melakukan input data pasien dalam form pendaftaran pasien baru ataupun lama untuk melakukan pendaftaran pasien.

3. Sistem dapat melakukan input data pasien pada form pelayanan untuk memberikan pemeriksaan, penanganan maupun pengobatan yang sesuai dengan kebutuhan pasien kepada pasien yang sudah di daftarkan.

4. Sistem ini dapat melakukan pembayaran apabila ada pasien yang dilakukan tindakan di puskesmas sedangkan pasien tersebut tidak memiliki asuransi atau jaminan kesehatan sehingga diperlukan pembayaran terhadap tindakan yang telah dilakukan dalam pembayaran juga berisi tentang hasil diagnosa pasien dan berisi jumlah dan aturan minum obat yang diberikan pada pasien.

5. Dengan sistem ini petugas dapat melihat data laporan jumlah kunjungan.

\section{Analisis Kebutuhan Pengguna}

Analisis Kebutuhan Pengguna merupakan tahapan penting dalam membangun sistem. Spesifikasi mengenai semua kebutuhan yang diinginkan oleh pengguna pada tahap ini. Hasil dari analisa kebutuhan pengguna ini digunakan untuk membangun kerangka siste

Adapaun Spesifikasi kebutuhan pengguna yang akan diterapkan pada sistem ini berdasarkan masing - masing pengguna adalah sebagai berikut :

1. Admin

a. Admin dapat membackup data pada database

b. Admin dapat menambahkan, mengubah dan menghapus user

c. Admin dapat melihat laporan kunjungan pasien

d. Admin dapat melihat laporan pendapatan puskesmas

e. Admin dapat menambah, mengubah dan menghapus data obat

2. Loket

a. Dapat mendaftarkan pasien 
b. Dapat mengubah data pasien yang sudah terdaftar atau disebut pasien lama

c. Dapat melihat data laporan kunjungan pasien

d. Dapat mencetak laporan kunjungan pasien

3. Dokter

a. Dapat melakukan input pemeriksaan pasien

b. Dapat melakukan input tindakan pasien

c. Dapat melakukan input pengobatan pasien

d. Dapat menambah, mengubah dan menghapus data diagnosa pelayanan

4. Apoteker

a. Dapat mengubah data satuan obat

b. Dapat menambah, mengubah dan menghapus data obat

5. Kasir

a. Dapat melakukan transaksi pembayaran tindakan

b. Dapat melihat laporan pendapatan puskesmas

c. Dapat meihat jumlah dan aturan obat yang diberikan pada pasien.

\section{Entity Relationship Diagram (ERD)}

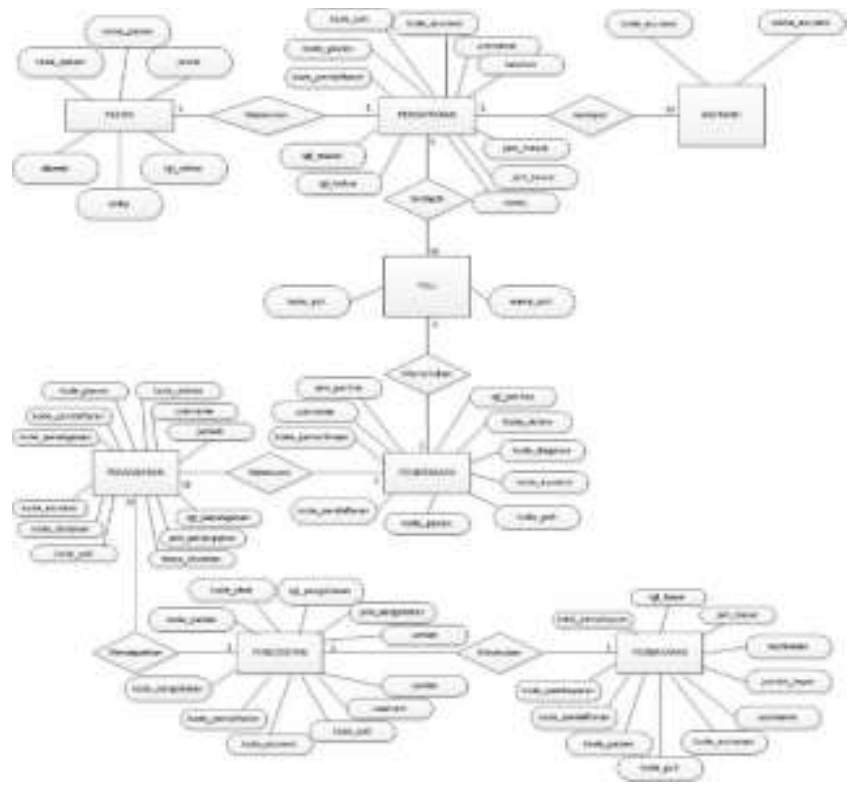

Gambar 3. Entity Relationship Diagram
Logical Record Structure (LRS)
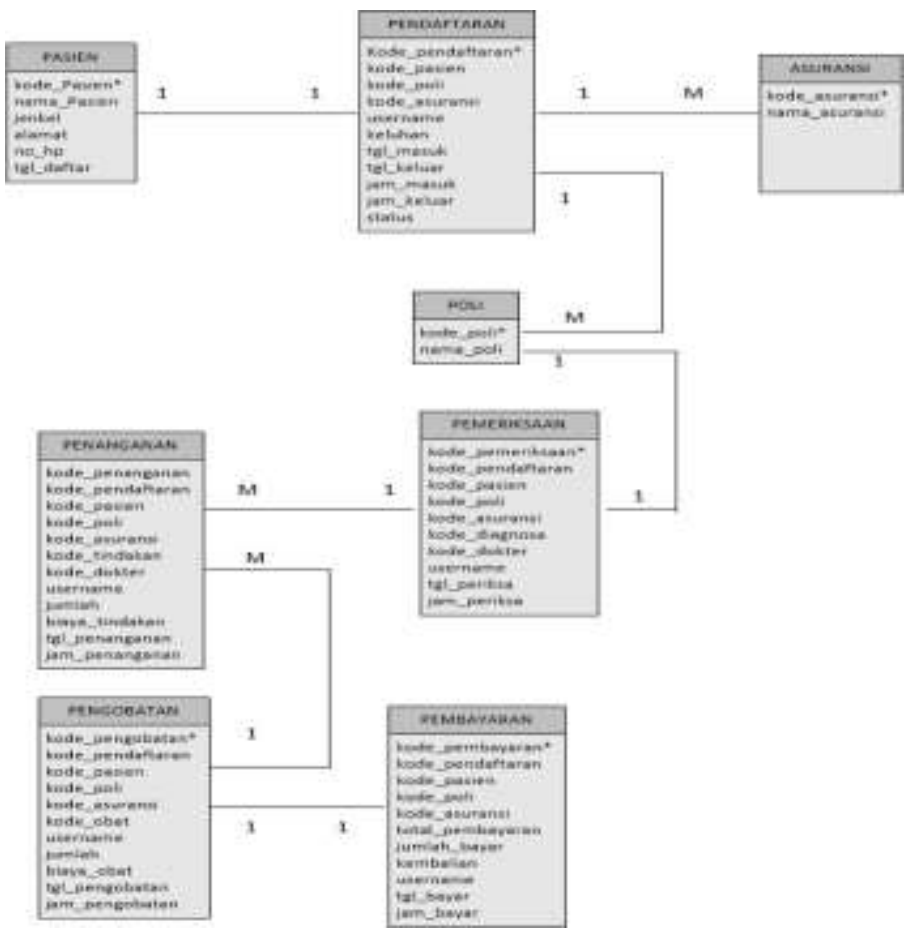

Gambar 4. Logical Record Structure

\section{Spesifikasi Sistem Komputer}

\section{Hardware}

- Processor Intel Core I3-4005U

- CPU 1.70 Ghz

- $\quad$ RAM 2.00GB

- Mouse

- Keyboard

- Monitor

- Printer

- Koneksi Internet

\section{Software}

- Sistem Operasi : Windows 10

- Aplikasi Web Server : Xampp v3.2.2

- Aplikasi Apache 2.4.23

- Aplikasi MySql 5.011

- Aplikasi PHPMyAdmin127.0.0.1

- Aplikasi Web Server : Mozilla Firefox, Google Chrome, Internet Explorer

\section{Implementasi Antar Muka}

Implementasi rancangan antar muka berdasarkan hasil rancangan antar muka. 
1. Implementasi Login

Halaman ini merupakan halaman awal program.

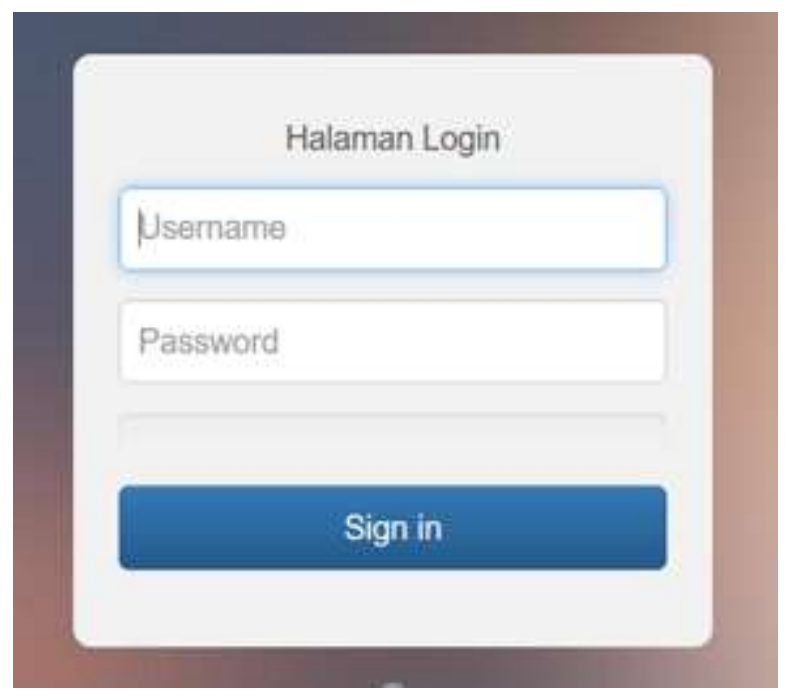

Gambar 5. Halaman Implementasi Login

\section{Implementasi Menu Admin}

Halaman ini merupakan halaman setelah Login sebagai Admin.

a. Halaman Home Admin

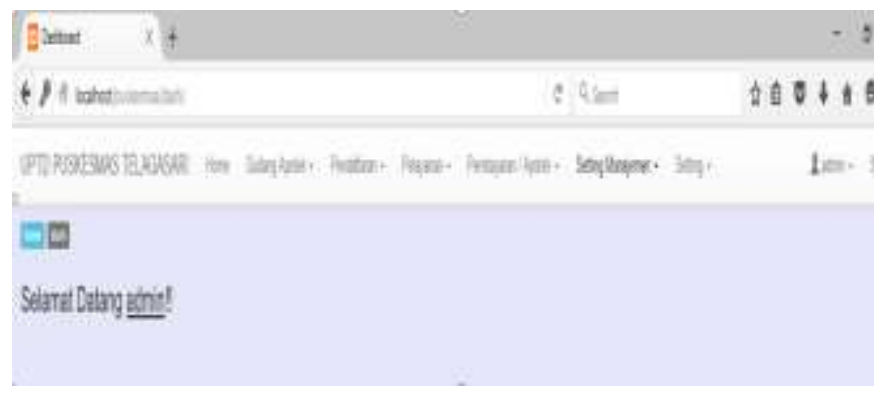

\section{Gambar 6. Menu Home}

b. Halaman Setting Manajemen Poli

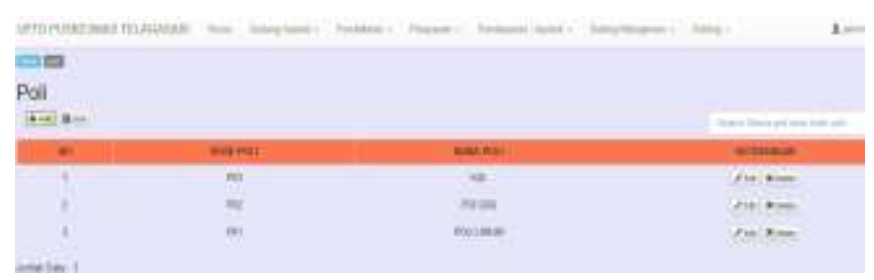

Gambar 7. Setting Manajemen Poli

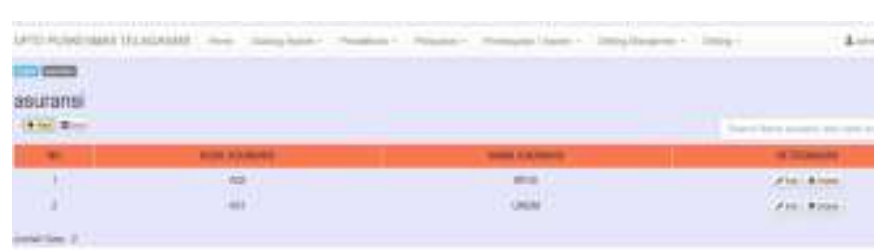

Gambar 8. Halaman Setting Manajemen Asuransi

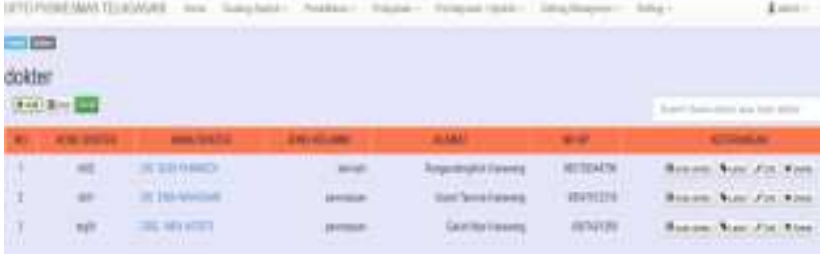

Gambar 9. Setting Manajemen Dokter

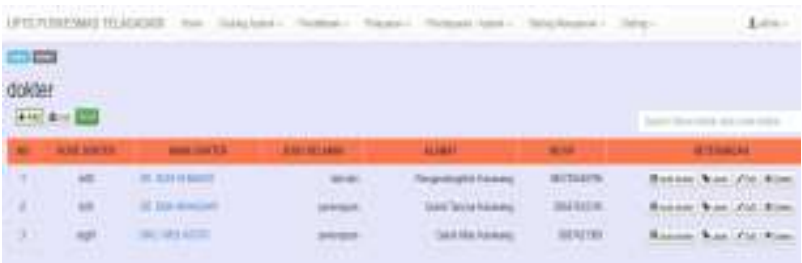

Gambar 10. Halaman Setting Manajemen Tindakan

\section{Halaman Pendaftaran}

Halaman Pendaftaran terdiri dari bebebrapa bagian halaman yaitu :

a. Halaman Data Pasien

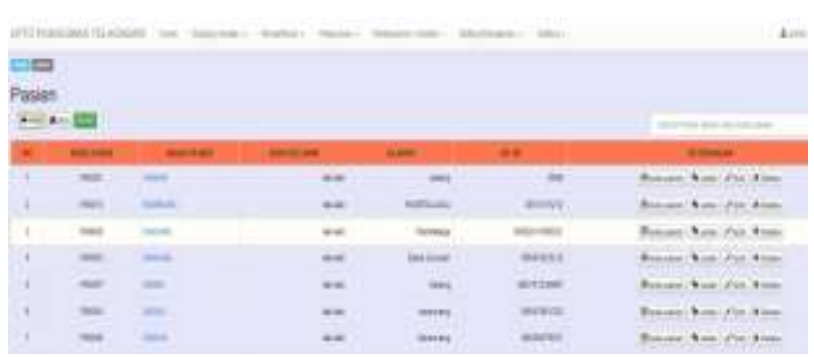

Gambar 11. Data Pasien

b. Halaman Form Pendaftaran Pasien

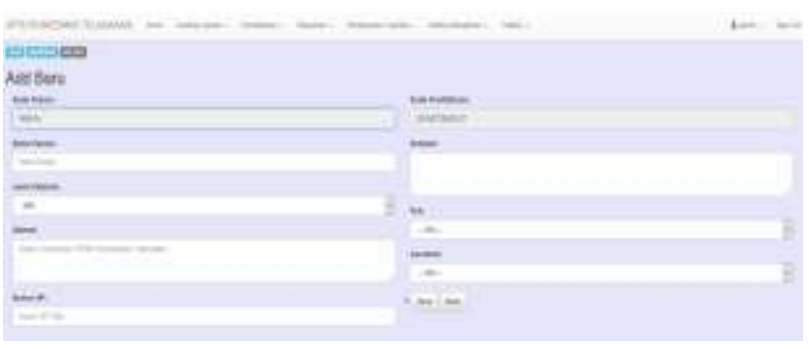

Gambar 12. Form Pendaftaran Pasien Baru

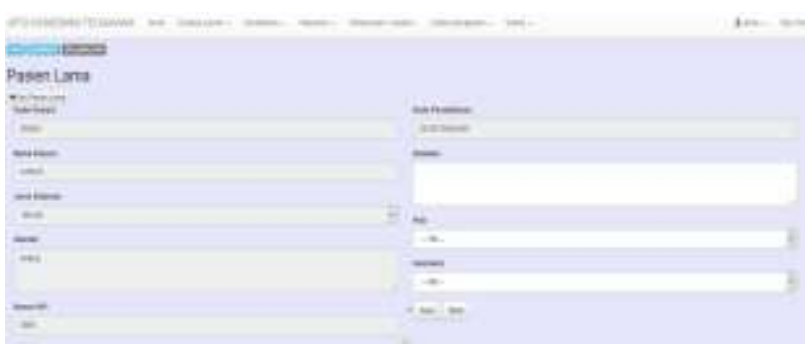

Gambar 13. Form Pendaftaran Pasien Lama 


\section{c. Halaman Laporan Kunjungan Pasien}

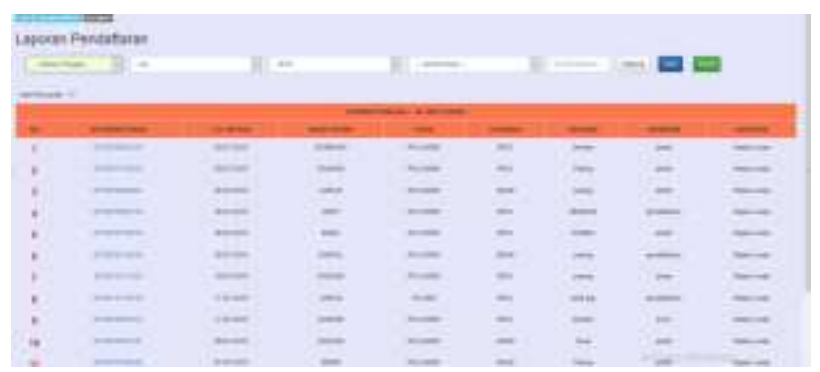

Gambar 14. Laporan Kunjungan Pasien

\section{Halaman Pelayanan}

Halaman Pelayanan ini terdiri dari pelayanan pemeriksaan, pelayanan penanganan, pelayanan data diagnosa.

\section{a. Halaman Pelayanan Pemeriksaan}

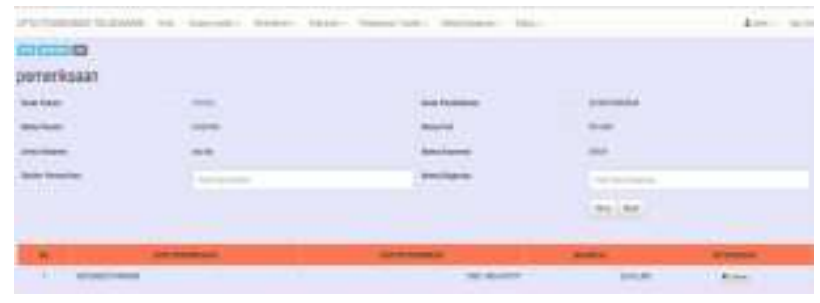

Gambar 15. Halaman Pelayanan Pemeriksaan

\section{b. Halaman Pelayanan Penanganan}

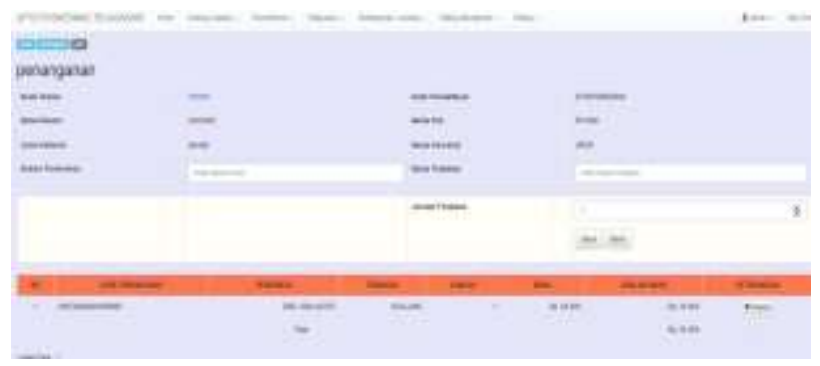

Gambar 16. Halaman Pelayanan Penanganan

\section{Pengujian Web}

Menurut Rosa dan Shalahuddin dalam (E. Fridayanthie, 2016), "Black-box testing adalah perangkat lunak dari segi spesifikasi fungsional tanpa menguji desain dan kode program". Pengujian web yang dilakukan pada kesempatan ini, menggunakan metode black box testing.

\section{Tabel 1. Pengujian Login Admin}

\begin{tabular}{|c|c|c|c|c|}
\hline $\begin{array}{c}\text { Skenario } \\
\text { Pengujia } \\
\text { n }\end{array}$ & Text Case & $\begin{array}{c}\text { Hasil } \\
\text { yang } \\
\text { diharapk } \\
\text { an }\end{array}$ & $\begin{array}{l}\text { Hasil } \\
\text { peng } \\
\text { ujian }\end{array}$ & $\begin{array}{c}\text { Kesimp } \\
\text { ulan }\end{array}$ \\
\hline $\begin{array}{l}\text { Username } \\
\text { dan } \\
\text { Passrod } \\
\text { tidak di isi } \\
\text { kemudian } \\
\text { klik } \\
\text { tombol } \\
\text { login }\end{array}$ & $\begin{array}{l}\text { Username } \\
: \text { (Kosong) } \\
\text { Password } \\
\text { : (Kosong) }\end{array}$ & $\begin{array}{l}\text { Sistem akan } \\
\text { menolak } \\
\text { akses user } \\
\text { dan akan } \\
\text { tetap di } \\
\text { halaman } \\
\text { login }\end{array}$ & $\begin{array}{c}\text { Sesua } \\
\text { i } \\
\text { Hara } \\
\text { pan }\end{array}$ & Valid \\
\hline $\begin{array}{l}\text { Mengisi } \\
\text { Username } \\
\text { dan } \\
\text { Password } \\
\text { tetapi } \\
\text { dengan } \\
\text { data yang } \\
\text { salah } \\
\text { kemudian } \\
\text { klik } \\
\text { tombol } \\
\text { login }\end{array}$ & $\begin{array}{l}\text { Username } \\
\text { : Kryawan } \\
\text { (salah) } \\
\text { Password } \\
: \quad 1234 \\
\text { (salah) }\end{array}$ & $\begin{array}{l}\text { Sistem akan } \\
\text { menolak } \\
\text { akses user } \\
\text { dan } \\
\text { menampilk } \\
\text { an "Error! } \\
\text { Wrong } \\
\text { Username } \\
\text { or } \\
\text { Password!" } \\
\text { dan akan } \\
\text { tetap di } \\
\text { halaman } \\
\text { login }\end{array}$ & $\begin{array}{l}\text { Sesua } \\
\mathrm{i} \\
\text { Hara } \\
\text { pan }\end{array}$ & Valid \\
\hline $\begin{array}{l}\text { Mengisi } \\
\text { Username } \\
\text { dan } \\
\text { Password } \\
\text { dengan } \\
\text { salah } \\
\text { kondisi } \\
\text { data yang } \\
\text { salah } \\
\text { kemudian } \\
\text { klik } \\
\text { tombol } \\
\text { login }\end{array}$ & $\begin{array}{l}\text { Username } \\
: \\
\text { pendaftar } \\
\text { an/apote } \\
\mathrm{k} / \text { pelaya } \\
\text { nan/kasir } \\
\text { (benar) } \\
\text { Password } \\
: \quad 1234 \\
\text { (salah) }\end{array}$ & $\begin{array}{l}\text { Sistem akan } \\
\text { menolak } \\
\text { akses user } \\
\text { dan } \\
\text { menampilk } \\
\text { an "Error! } \\
\text { Wrong } \\
\text { Username } \\
\text { or } \\
\text { Password!" } \\
\text { dan akan } \\
\text { tetap di } \\
\text { halaman } \\
\text { login }\end{array}$ & $\begin{array}{l}\text { Sesui } \\
\text { a } \\
\text { Hara } \\
\text { pan }\end{array}$ & Valid \\
\hline $\begin{array}{l}\text { Mengisi } \\
\text { Username } \\
\text { dan } \\
\text { Password } \\
\text { dengan } \\
\text { usernama } \\
\text { dan } \\
\text { password } \\
\text { data yang } \\
\text { benar } \\
\text { kemudian } \\
\text { klik } \\
\text { tombol } \\
\text { login }\end{array}$ & $\begin{array}{l}\text { Username } \\
: \\
\text { pendaftar } \\
\text { an/apote } \\
\mathrm{k} / \text { pelaya } \\
\text { nan/kasir } \\
\text { (benar) } \\
\text { Password } \\
: \quad 12345 \\
\text { (benar) }\end{array}$ & $\begin{array}{l}\text { Berhasil } \\
\text { Masuk ke } \\
\text { halaman } \\
\text { menu } \\
\text { admin }\end{array}$ & $\begin{array}{l}\text { Sesua } \\
\text { i } \\
\text { Hara } \\
\text { pan }\end{array}$ & Valid \\
\hline
\end{tabular}


Tabel 2. Pengujian Pendaftaran Pasien

\begin{tabular}{|c|c|c|c|c|}
\hline $\begin{array}{c}\text { Skenario } \\
\text { Pengujian }\end{array}$ & Text Case & $\begin{array}{l}\text { Hasil yang } \\
\text { diharapkan }\end{array}$ & $\begin{array}{l}\text { Hasil } \\
\text { peng } \\
\text { ujian }\end{array}$ & Kesimpulan \\
\hline $\begin{array}{l}\text { Nama } \\
\text { Pasien, } \\
\text { Jenis } \\
\text { kelamin, } \\
\text { Alamat, } \\
\text { Nomor } \\
\text { HP, } \\
\text { Keluhan } \\
\text { poli dan } \\
\text { asuransi } \\
\text { tidak di isi } \\
\text { kemudian } \\
\text { klik } \\
\text { tombol } \\
\text { simpan }\end{array}$ & 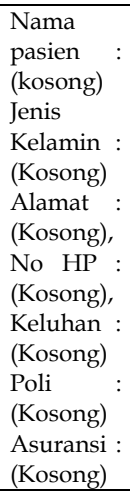 & $\begin{array}{l}\text { Sistem akan } \\
\text { menolak } \\
\text { untuk } \\
\text { menyimpan } \\
\text { data } \\
\text { tersebut dan } \\
\text { akan tetap } \\
\text { di form } \\
\text { pendaftaran } \\
\text { pasien }\end{array}$ & $\begin{array}{c}\text { Sesua } \\
\text { i } \\
\text { Hara } \\
\text { pan }\end{array}$ & Valid \\
\hline $\begin{array}{l}\text { Nama } \\
\text { Pasien di } \\
\text { isi } \\
\text { sedangka } \\
\mathrm{n} \text { Jenis } \\
\text { kelamin, } \\
\text { Alamat, } \\
\text { Nomor } \\
\text { HP, } \\
\text { Keluhan } \\
\text { poli dan } \\
\text { asuransi } \\
\text { tidak di } \\
\text { isi } \\
\text { kemudian } \\
\text { klik } \\
\text { tombol } \\
\text { simpan }\end{array}$ & 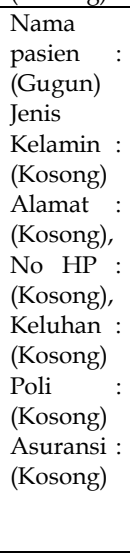 & $\begin{array}{l}\text { Sistem akan } \\
\text { menolak } \\
\text { untuk } \\
\text { menyimpan } \\
\text { data tersebut } \\
\text { dan akan tetap } \\
\text { di form } \\
\text { pendaftaran } \\
\text { pasien }\end{array}$ & $\begin{array}{c}\text { Sesua } \\
\text { i } \\
\text { Hara } \\
\text { pan }\end{array}$ & Valid \\
\hline $\begin{array}{l}\text { Nama } \\
\text { Pasien, } \\
\text { Jenis } \\
\text { kelamin, } \\
\text { Alamat, } \\
\text { Nomor } \\
\text { HP, di isi } \\
\text { sedangka } \\
\text { n } \\
\text { Keluhan } \\
\text { poli dan } \\
\text { asuransi } \\
\text { tidak di } \\
\text { isi } \\
\text { kemudian } \\
\text { klik } \\
\text { tombol } \\
\text { simpan }\end{array}$ & 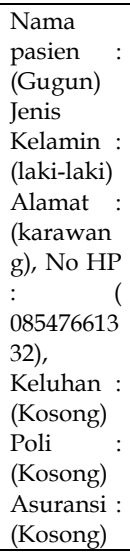 & $\begin{array}{l}\text { Sistem akan } \\
\text { menolak } \\
\text { untuk } \\
\text { menyimpan } \\
\text { data tersebut } \\
\text { dan akan tetap } \\
\text { di form } \\
\text { pendaftaran } \\
\text { pasien }\end{array}$ & $\begin{array}{c}\text { Sesua } \\
\text { i } \\
\text { Hara } \\
\text { pan }\end{array}$ & Valid \\
\hline $\begin{array}{l}\text { Nama } \\
\text { Pasien, } \\
\text { Jenis } \\
\text { kelamin, } \\
\text { Alamat, } \\
\text { Nomor } \\
\text { HP, } \\
\text { Keluhan, } \\
\text { poli dan } \\
\text { asuransi } \\
\text { di isi } \\
\text { lengkap } \\
\text { kemudian } \\
\text { klik } \\
\text { tombol } \\
\text { simpan }\end{array}$ & 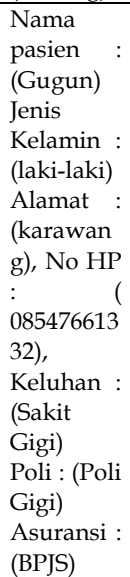 & $\begin{array}{l}\text { Sistem akan } \\
\text { menyimpan } \\
\text { data tersebut } \\
\text { dan akan } \\
\text { menampilkan } \\
\text { data pasien } \\
\text { tersebut }\end{array}$ & $\begin{array}{c}\text { Sesua } \\
\text { i } \\
\text { Hara } \\
\text { pan }\end{array}$ & Valid \\
\hline
\end{tabular}

Tabel 3. Pengujian Data Dokter

\begin{tabular}{|c|c|c|c|c|}
\hline $\begin{array}{c}\text { Skenario } \\
\text { Pengujian }\end{array}$ & Text Case & $\begin{array}{c}\text { Hasil } \\
\text { yang } \\
\text { diharapk } \\
\text { an }\end{array}$ & $\begin{array}{l}\text { Hasil } \\
\text { peng } \\
\text { ujian }\end{array}$ & $\begin{array}{c}\text { Kesi } \\
\text { mpul } \\
\text { an }\end{array}$ \\
\hline $\begin{array}{l}\text { Kode } \\
\text { Dokter, } \\
\text { Nama } \\
\text { Dokter, } \\
\text { Jenis } \\
\text { kelamin, } \\
\text { Alamat, } \\
\text { Nomor HP, } \\
\text { tidak di isi } \\
\text { kemudian } \\
\text { klik tombol } \\
\text { simpan }\end{array}$ & 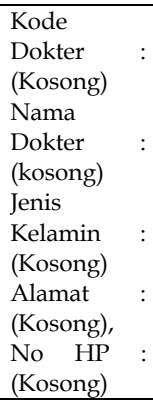 & $\begin{array}{l}\text { Sistem } \\
\text { akan } \\
\text { menolak } \\
\text { untuk } \\
\text { menyimp } \\
\text { an data } \\
\text { tersebut } \\
\text { dan akan } \\
\text { tetap di } \\
\text { form } \\
\text { tambah } \\
\text { data } \\
\text { dokter } \\
\end{array}$ & $\begin{array}{c}\text { Sesua } \\
\text { i } \\
\text { Hara } \\
\text { pan }\end{array}$ & Valid \\
\hline $\begin{array}{l}\text { Kode } \\
\text { Dokter, di } \\
\text { isi } \\
\text { sedangkan } \\
\text { Nama } \\
\text { Dokter, } \\
\text { Jenis } \\
\text { kelamin, } \\
\text { Alamat, } \\
\text { Nomor HP, } \\
\text { tidak di isi } \\
\text { kemudian } \\
\text { klik tombol } \\
\text { simpan }\end{array}$ & 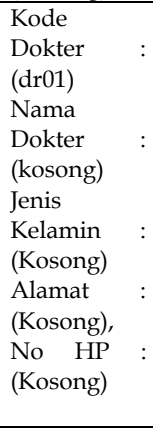 & $\begin{array}{l}\text { Sistem } \\
\text { akan } \\
\text { menolak } \\
\text { untuk } \\
\text { menyimp } \\
\text { an data } \\
\text { tersebut } \\
\text { dan akan } \\
\text { tetap di } \\
\text { form } \\
\text { tambah } \\
\text { data } \\
\text { dokter }\end{array}$ & $\begin{array}{c}\text { Sesua } \\
\text { i } \\
\text { Hara } \\
\text { pan }\end{array}$ & Valid \\
\hline $\begin{array}{l}\text { Kode } \\
\text { Dokter, } \\
\text { Nama } \\
\text { Dokter, } \\
\text { Jenis } \\
\text { kelamin di } \\
\text { isi } \\
\text { sedangkan } \\
\text { Alamat, } \\
\text { Nomor HP, } \\
\text { tidak di isi } \\
\text { kemudian } \\
\text { klik tombol } \\
\text { simpan }\end{array}$ & 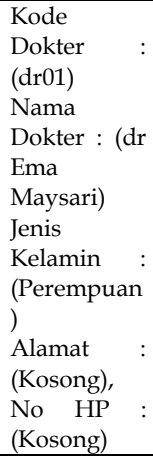 & $\begin{array}{l}\text { Sistem } \\
\text { akan } \\
\text { menolak } \\
\text { untuk } \\
\text { menyimp } \\
\text { an data } \\
\text { tersebut } \\
\text { dan akan } \\
\text { tetap di } \\
\text { form } \\
\text { tambah } \\
\text { data } \\
\text { dokter }\end{array}$ & $\begin{array}{c}\text { Sesua } \\
\text { i } \\
\text { Hara } \\
\text { pan }\end{array}$ & Valid \\
\hline $\begin{array}{l}\text { Kode } \\
\text { Dokter, } \\
\text { Nama } \\
\text { Dokter, } \\
\text { Jenis } \\
\text { kelamin, } \\
\text { Alamat, } \\
\text { Nomor HP, } \\
\text { di isi } \\
\text { lengkapkem } \\
\text { udian klik } \\
\text { tombol } \\
\text { simpan }\end{array}$ & 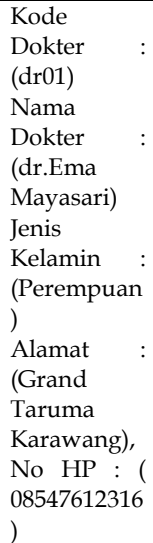 & $\begin{array}{l}\text { Sistem } \\
\text { akan } \\
\text { menyimp } \\
\text { an data } \\
\text { tersebut } \\
\text { dan } \\
\text { menampil } \\
\text { kan data } \\
\text { dokter } \\
\text { tersebut }\end{array}$ & $\begin{array}{c}\text { Sesua } \\
\text { i } \\
\text { Hara } \\
\text { pan }\end{array}$ & Valid \\
\hline
\end{tabular}

\section{Kesimpulan \& Saran}

Berdasarkan uraian yang telah dibahas dalam bab-bab sebelumnya dapat diambil beberapa kesimpulan yang dapat diambil dari perancangan program aplikasi pelayanan di puskesmas ini yaitu :

1. Dengan pembuatan program aplikasi rawat jalan ini sebagai salah satu langkah awal 
puskesmas meningkatkan pelayanan di puskesmas.

2. Dengan aplikasi program rawat jalan ini dapat mengurangi kesalahan-kesalahan yang terjadi pada sistem yang masih manual.

Dengan penggunaan program aplikasi rawat jalan dalam proses kegiatan pelayanan rawat jalan di puskesmas. Disini penulis mencoba memberikan sedikit saran kepada Puskesmas Telagasari agar dalam pengolahan data terlaksana dengan baik,antara lain:

1. Agar Kepala Puskesmas Telagasari untuk memberikan pelatihan singkat kepada petugas yang masih belum bisa menggunakan komputer karena program aplikasi sebagus apapun kalau tidak dibarengi dengan Sumber Daya Manusianya akan tidak sempurna proses penggunaannya.

2. Untuk petugas admin agar setiap waktu berkala untuk membackup data untuk menghindari kehilangan data.

\section{Referensi}

[1] Sagita, R. A., \& Sugiarto, H. (2016). Penerapan Metode Waterfall Pada Sistem Informasi Penjualan Furniture Berbasis Web. On Networking and Security, 5(4), 4955.

[2] Syahriani. (2018). Sistem Informasi Pelayanan Kesehatan Berbasis Web pada Puskesmas Pluit Jakarta. Jurnal Ilmiah Informatika Komputer STMIK Nusa Mandiri, $\quad$ IV(2), 105-111. https://doi.org/10.31294/jtk.v4i2.3457

[3] E. Fridayanthie, T. M. (2016). RANCANG BANGUN SISTEM INFORMASI PERMINTAAN ATK BERBASIS INTRANET (STUDI KASUS: KEJAKSAAN NEGERI RANGKASBITUNG). IOSR Journal of Economics and Finance, 3(1), 56. https://doi.org/https://doi.org/10.3929/ ethz-b-000238666
[4] Hartiwi, Y. (2018). Analisis dan Implementasi Sistem Informasi Penjualan Berbasis Web Pada Ukm Tiara Batam. Jurnal Responsive, 2(2), 37.

[5] Hendriansyah. (2014). Implementasi data flow diagram pada perancangan website ecommerce. Jurnal IPTEK, (Juli), 31-48.

[6] Kadek Wibowo. (2015). Analisa Konsep Object Oriented Programming Pada Bahasa Pemrograman Php. Khatulistiwa Informatikaw, 3(2), 151-159.

[7] Prabowo, D. (2015). Website E-Commerce Menggunakan Model View Controller ( Mvc ) Dengan Framework Codeigniter. Dasi, 16(1), 23-29.

[8] Sunarti. (2015). Jurnal Evolusi Volume 3 No 2 - 2015 - lppm3.bsi.ac.id/jurnal. Jurnal Evolusi, 3(2), 1-8.

[9] Y.E Achyani, E. A. (2017). Sistem Informasi Pendapatan Jasa Berbasis Web Pada Koperasi Pdam Tirta Patriot Bekasi. INFORMATIKA Diterima Agustus Revisi Agustus Disetujui Agustus, 1(6), 178-185.

[10]Kadir, A. (2014). Pengenalan Sistem Informasi Edisi Revisi. American Enterprise Institute for Public Policy Research, 14(28), 50-55. https:// doi.org/10.13140/2.1.2637.632

[11]Lukman Ahmad, M. (2018). Sistem Informasi Manajemen : Buku Refrensi.

[12]PERMENKES. (2014). PERATURAN MENTERI KESEHATAN REPUBLIK INDONESIA NOMOR 75 TAHUN 2014 TENTANG KESEHAATAN MASYARAKAT. 561-565. 